\title{
Reflecting on Critical Incidents in Language Education: 40 Dilemmas for Novice TESOL Professionals
}

\author{
Thomas S. C. Farrell, Laura Baecher \\ Bloomsbury, 2017 (paperback; publisher's list price \$26.95) \\ 161 pages, ISBN 978-1-4742-5583-7
}

Teaching English as a second or other language (TESOL) requires a complex set of skills, and English-language teachers, from novice to expert, continually encounter challenging issues and situations - "critical incidents" - in their daily practice in a wide range of settings. Teachers may find some of these challenges unfamiliar or difficult, depending on the training or preparation they have undergone; these incidents also require consideration and reflection on the teachers' part to formulate appropriate and principled responses. This book examines a wide variety of these critical incidents and provides some helpful directions for reflection.

Each of the book's 10 chapters examines a different topic illustrated by four critical incidents drawn from experiences of teachers in real-life classrooms. The topics include creating a positive classroom community, curriculum development, teaching mixed-level/large classes, classroom management, developing students' speaking skills, developing students' reading skills, developing students' listening skills, developing students' writing skills, addressing workplace challenges, and professional development.

Among the 40 incidents are some that novice teachers commonly experience in settings they may already be familiar with, such as teaching younger learners, working in countries where English is not a dominant language locally, or following curricula that are prescribed to varying degrees. Other incidents may be more particular, but by no means uncommon, such as addressing special needs or poverty, dealing with unfamiliar cultural expectations, or navigating dynamics in the workplace or among colleagues.

The 10 chapters follow a consistent structure, beginning with inquiry questions from teachers about the critical incidents at hand, followed by preview questions put forth by the authors to prime the reader to consider the issues, then a detailed description of the situations and settings accompanied 
by the teachers' response, and finally some follow-up tasks and questions for the reader to consider the issues further.

As the book is expressly aimed at teachers relatively new to the profession, it contains plenty of helpful guidance and useful suggestions. For example, a novice teacher might have a conversation with a mentor teacher to find out what she or he does to orient new staff members (chap. 10), or a teacher can mentally prepare questions for an administrator before sitting down to discuss certain curriculum elements (chap. 2). Other ideas are more directly related to practical concerns in the classroom, such as how best to provide corrective feedback for written work (chap. 8), or ways to help students develop better understanding of transactional talk in listening lessons (chap. 7).

More experienced teachers and teacher educators may also be able to use this book "as a refresher on the various dilemmas that can appear in any classroom" (p. 6). This is clear from some of the more delicate problems raised, such as addressing special needs or issues related to poverty among students. More experienced teachers and teacher educators can also use questions in the preview section in each chapter to provide further guidance and direction if newer teachers should find these dilemmas to be beyond their current experience or insight.

Because of the complex nature and demands of TESOL, not all conceivable issues could be addressed in one volume. Areas such as practicing language for communicative purposes in classroom settings, ways to address or navigate the still common notion of native speaker versus non-native speaker teachers, or Lesbian, Gay, Bisexual, Transgender, Queer (LGBTQ)-related issues, to name only a few, might be worthy additions for a future edition.

This is a thoughtfully written book with accessible ideas that cover a wide range of issues. It should be very helpful for ESOL teachers as they begin their career, as well as more experienced teachers who may be able to use some of its theoretical and practical elements to help provide guidance to colleagues new to a field that is at once exciting and challenging, with potential for great satisfaction when critical incidents are met with principled responses based on critical reflection.

\section{Patrick Huang}

\section{The Reviewer}

Patrick Huang is an English-language teacher and teacher-educator and has delivered and assessed training courses in a range of international contexts and settings. Presently pursuing his PhD in Toronto, his research interests include areas such as teacher education and development, teacher identity, mentoring, intercultural learning and teaching, and reflective practice. 